\title{
In vitro Screening and Optimization of IAA Production from Plant Growth Promoting Rhizobacteria Burkholderia cepacia UPMB3
}

\section{Waheeda Parvin ${ }^{1 *}$, Quazi Shirin Akhter Jahan², Md. Mahbubur Rahman $^{1}$ and Mui Yun Wong}

Department of Plant Protection, Faculty of Agriculture, Universiti Putra Malaysia, 43400, Serdang, Selangor, Malaysia

Key words: Burkholderia cepacia UPMB3, Optimisation, In vitro, Oil palm

\begin{abstract}
Burkholderia cepacia UPMB3 is an important plant growth promoting rhizobacteria isolated from oil palm rhizosphere which is considered to promote plant growth directly or indirectly. The IAA was extracted, purified, detected and confirmed by thin layer chromatography analyses from the strain UPMB3 of B. cepacia. $R_{f}$ value was compared with the authentic IAA. Maximum $50 \mu \mathrm{g} / \mathrm{ml}$ IAA was produced in the medium supplemented with 4 $\mathrm{mg} / \mathrm{ml}$ L-tryptophan, under shaken conditions at $150 \mathrm{rpm}$ in seven days incubation at $\mathrm{pH}$ 7. The bacterial extract significantly influenced the growth of oil palm seedlings producing shoot, root, leaf and leaf length compared to control.
\end{abstract}

\section{Introduction}

The Burkholderia cepacia complex (Bcc) is a diverse group of bacteria commonly found in soil, water, and the rhizosphere. It comprises 19 species, which includes soil and rhizosphere bacteria as well as plant and human pathogens (Paulina et al. 2001). Different Burkholderia species have been emerged as a potentially promising group of plant growth-promoting rhizobacteria (PGPR). Approximately $80 \%$ of rhizosphere bacteria can secrete IAA (Bhavdish et al. 2003). It is likely that plant growth promotion by rhizobacteria is the result of combined action of several ways. But the production of phytohormones (specially IAA) is considered as a direct mechanism used by bacteria to

*Author for correspondence: «aheeda_bfri@yahoo.com>. 1,Bangladesh Forest Research Institute, Chittagong, Bangladesh. ${ }^{2}$ Bangladesh Rice Research Institute, Gazipur, Bangladesh. 
increase the growth and yield of plants (Idris et al. 2007). The phytohormone auxins play a central role in plant growth and development as a regulator of numerous biological processes. IAA is the member of this group of phytohormones and a product of L-tryptophan metabolism in microorganisms. Bacteria that inhabit the rhizosphere may influence plant growth by contributing to a host plant's endogenous pool of bioactive compounds such as phytohormones, antibiotics, siderophores. IAA is one of the most physiologically active auxins and a common product of L-tryptophan metabolism by several microorganisms including PGPR. PGPR could be a great ecological and agricultural importance, if they are reliably used in place of chemical fertilizers and pesticides without being pathogenic to plants. Bacterial production of IAA has been studied not only regarding its physiological effects on plants but also regarding its possible role as a phytohormone in plant - microbe interaction. The roles of PGPR have been extensively studied as biofertilizers to increase the yield of agronomically important crops. This study was conducted to detect and optimise the IAA production by Burkholderia cepacia UPMB3 and its influence on oil palm seedling growth.

\section{Materials and Methods}

The strain Burkholderia cepacia UPMB3 (Fig.1) was isolated from roots of oil palm and was confirmed by the Biolog ${ }^{\circledR}$ identification system (version 4.2) (Zaiton et al. 2006). The bacterium was collected from Plant Protection Department, Universiti Putra Malaysia.
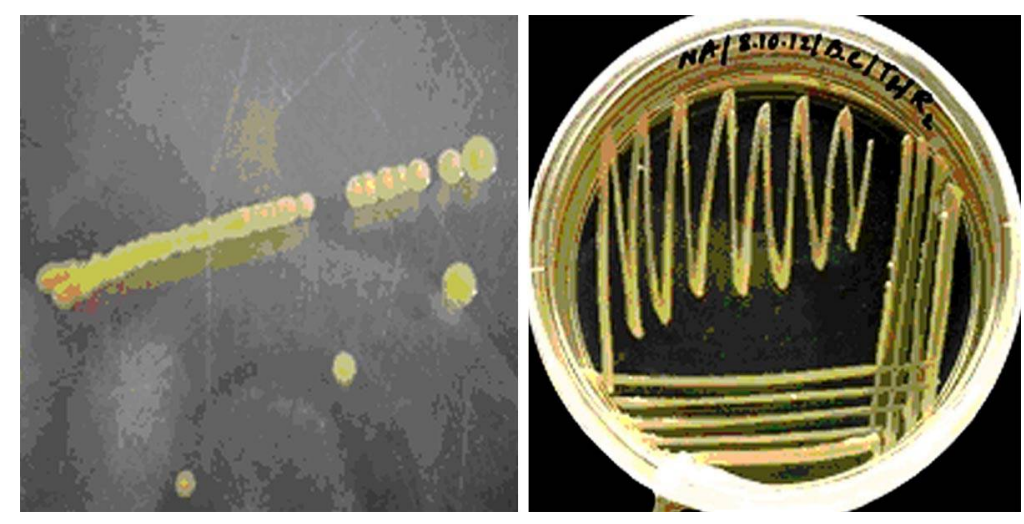

Fig. 1. Rhizobacterial strain Burkholderia cepacia UPMB3.

It was cultured in NB supplemented with L-tryptophan, adjusted $\mathrm{pH}$ to 7.0 and incubated at $28 \pm 2^{\circ} \mathrm{C}$ on a rotary shaker at $150 \mathrm{rpm}$ for seven days. The bacterial cell-free supernatant was harvested by centrifugation at 10,000 rpm 
for $15 \mathrm{~min}$ at $4^{\circ} \mathrm{C}$ and used for extraction of IAA. For screening of IAA, the bacterial supernatant was mixed with ortho-phosphoric acid and Salkowski's reagent. Mixtures were incubated at room temperature for $30 \mathrm{~min}$ and observed for pink color production. The colour change was recorded in the spectrophotometer at $530 \mathrm{~nm}$.

IAA was extracted and purified following the method described by Tien et al. (1979) with some modifications. The bacterial supernatant was reduced by rotatory evaporator and acidified. The supernatant was extracted with ethyl acetate then evaporated to dry at $40^{\circ} \mathrm{C}$ and dissolved in methanol. After filtering through $0.45 \mu \mathrm{m}$ membrane filter the extract was kept at $-20^{\circ} \mathrm{C}$. For the confirmation of IAA production, it was detected by thin-layer chromatography analysis. Silica gel thin layer chromatography (TLC) was found to be a powerful technique in purification, separation and possible identification of natural and synthetic indole derivatives. Thirty $\mathrm{ml}$ of extracted samples was plated on TLC plates and was run by the solvent system benzene : acetone : acetic acid $(6: 3: 1)$ and sprayed with Ehrlich's reagent. Spots with $\mathrm{R}_{f}$ values identical to authentic IAA were identified under UV light (254 and $365 \mathrm{~nm}$ ). The effect of Ltryptophan $(0-5 \mathrm{mg} / \mathrm{ml})$ and different $\mathrm{pH}$ level $(3,5,7$ and 10) on IAA production in NB medium was optimised. One per cent inoculum of O.D.600nm was incubated at $28 \pm 2^{\circ} \mathrm{C}$ for $3,5,7$ and 10 days, respectively under static and shaken (150 rpm) conditions in an incubator shaker. After incubation the broth was centrifuged at 10,000 rpm for $10 \mathrm{~min}$. Supernatant was collected. Two $\mathrm{ml}$ of Salkowski's reagent was added to $1 \mathrm{ml}$ supernatant and extent of pink colour showing IAA production was measured spectrophotometrically at $530 \mathrm{~nm}$.

The effect of IAA on germinated oil palm seeds was studied. The germinated oil palm seeds were surface sterilized with $95 \%$ ethanol for 2 min and then with 10\% Clorox for $15 \mathrm{~min}$. Successive washing was done with sterile distilled water to remove the chemicals completely. The seeds were separately soaked in $250 \mathrm{ml}$ of bacterial culture filtrate based on the production of IAA by the strain UPMB3 and synthetic IAA. Sterile distilled water was used as non-treated control treatment. Plastic pot experiment was carried out to observe the effect of IAA produced by B. cepacia UPMB3 strain on oil palm seedling growth. The seeds were soaked in each treatment for $48 \mathrm{hrs}$ and then planted in pots filled with sterile soil. The pots were kept in partial sunlight and observed daily including watering to maintain soil moisture. After 4 weeks, the plants were carefully uprooted and recorded data subsequently.

The experiment was arranged as completely randomized design. Three replications were used for each treatment and repeated twice. Data were 
analysed using statistical analysis system (SAS v9.3) and means were statistically compared using LSD test. The significance level was set up at $\mathrm{p}<0.05$.

\section{Results and Discussion}

The bacterial strain $B$. cepacia UPMB3 showed pink colour reaction with Salkowski's reagent indicating their ability to produce IAA (Fig. 2A). IAA production was confirmed by the appearance of blue bands with that of authentic IAA bands on pre-coated silica gel plates under UV (365 nm). The solvent system benzene : acetone : acetic acid was used to detect the IAA production by the bacterial strain. The $\mathrm{R}_{f}$ value was found 0.88 for $B$. cepacia

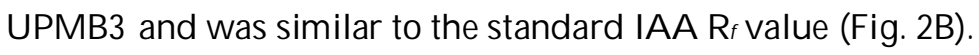

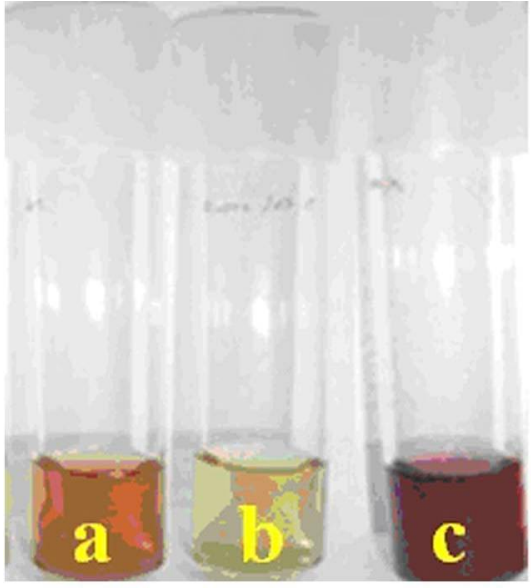

(A)

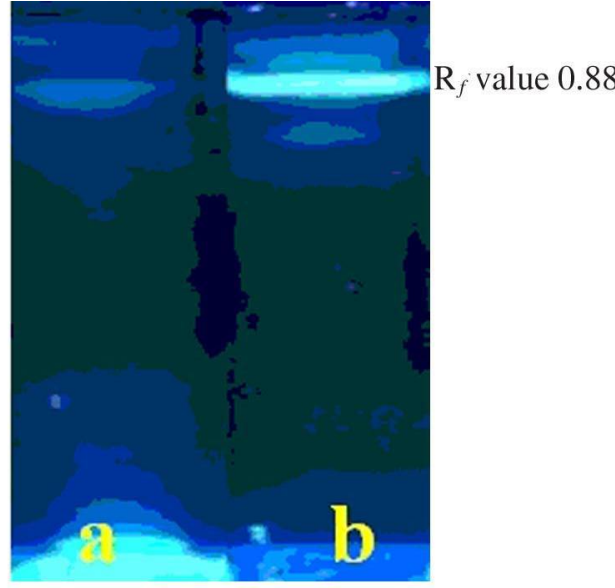

(B)

Fig. 2. (A) Screening of IAA production. $\mathrm{a}=$ B. cepacia UPMB3 (pink colour), $\mathrm{b}=$ B. cepacia UPMB3 (Control), $\mathrm{c}=$ Standard IAA. (B) Thin layer chromatography analysis. $\mathrm{a}=B$. cepacia $\mathrm{UPMB} 3, \mathrm{~b}=$ Standard IAA.

Ritika et al. (2012) reported that different isolates of Pseudomonas sp produced auxins like substances in the stationary phase of growth at $72 \mathrm{hrs}$ of incubation period at $28^{\circ} \mathrm{C}$. The homogeneity of the partially purified auxins was checked by thin layer chromatography and auxins gave the maximum $\mathrm{R}_{f}$ value of 0.81 in solvent system isopropanol: water (3:2). Pink spots corresponding to auxins or auxins like substances were visible when sprayed with Salper reagent. The IAA produced by the B. licheniformis MML2501 was confirmed by the appearance of blue bands with that of authentic IAA bands on TLC plates with $\mathrm{R}_{f}$ value 0.66 in solvent system isopropanol : ammonia : water $(8: 1: 1)$ and sprayed with Ehrlich's reagent (Prashanth and Mathivanan 2010). 
B. cepacia UPMB3 was found to be the efficient producer of IAA. The different concentrations of L-tryptophan in the culture medium influenced the IAA production. From the result, it was observed that the bacterial strain was able to produce a lower amount of IAA, without L-tryptophan. The maximum IAA production by $B$. cepacia UPMB3 was recorded $50.88 \mu \mathrm{g} / \mathrm{ml}$ at $4 \mathrm{mg} / \mathrm{ml} \mathrm{L-}$ tryptophan concentration (Fig. 3). IAA production was found to be decreased when the media were supplemented with $5 \mathrm{mg} / \mathrm{ml}$ L-tryptophan.

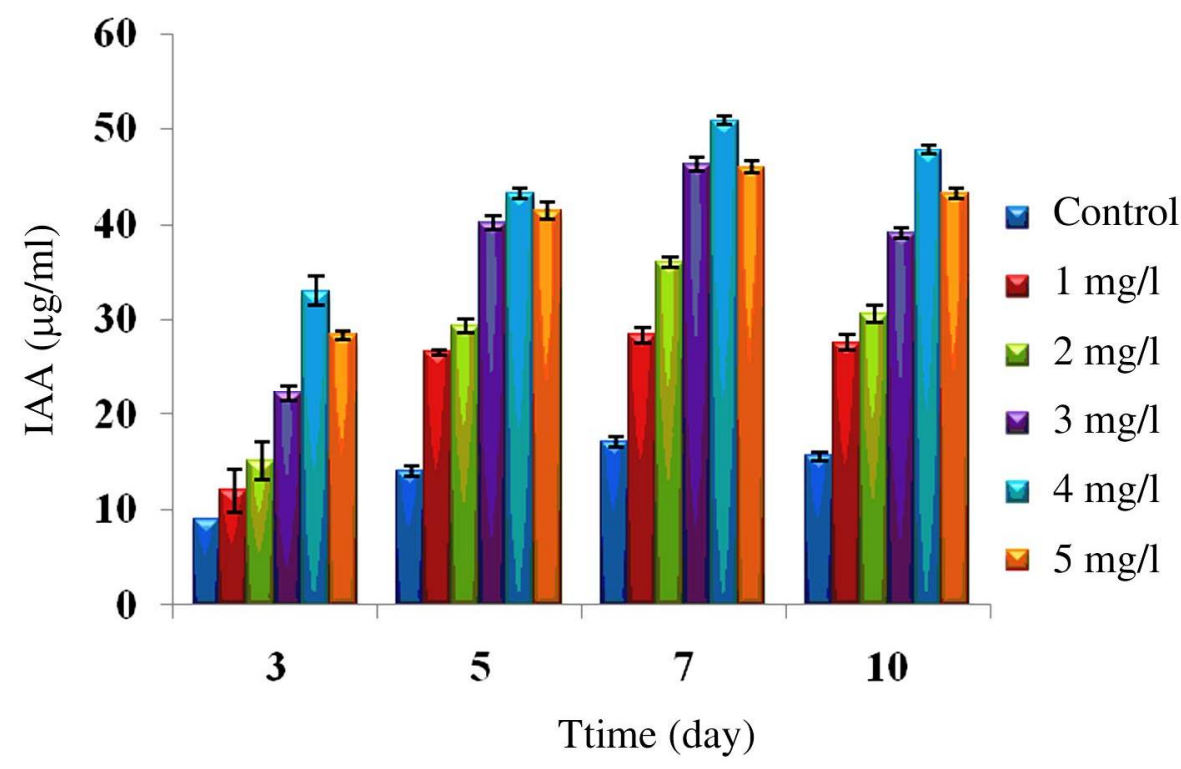

Fig. 3. Production of IAA by B. cepacia UPMB3 at various concentrations of L - tryptophan. Each value is the mean of 3 replications. Vertical bars represent standard error.

IAA production was found to be decreased when the media were supplemented with $5 \mathrm{mg} / \mathrm{ml}$ L-tryptophan in 10 days incubation. This decrease might be due to the release of IAA degrading enzymes such as IAA oxidase and peroxidase as reported earlier in Rhizobium sp. from Cajanus cajan (Datta and Basu 2000). Some other workers also observed in variable IAA production ability of bacteria. Ahmad et al. (2005) reported that rhizosphere Azotobacter spp. and Pseudomonas spp. produced a high level of IAA when these bacteria were cultured in a nutrient broth amended with 1,2 and $5 \mathrm{mg} / \mathrm{ml}$ of L-tryptophan. The concentration of IAA in P. fluorescens AK1 and P. aeruginosa AK2 isolates without L-tryptophan was 3.1 and $3.3 \mathrm{pmol} / \mathrm{ml}$. A further increase in IAA production was observed in the presence of different concentrations of L-tryptophan (100, 200 and $500 \mu \mathrm{g} / \mathrm{ml}$ ). A significant increase in the production of IAA was recorded in 
P. fluorescens AK1 and P. aeruginosa AK2 in the presence of 100, 200 and 500 $\mu \mathrm{g} / \mathrm{ml}$ of L-tryptophan, i.e. 3.8, 5.2 and $6.9,3.9,4.0$ and $4.2 \mathrm{pmol} / \mathrm{ml}$, respectively (Karnwal 2009).

To optimize the different levels of $\mathrm{pH}$ on IAA production, the bacterial strain was inoculated in NB medium supplemented with optimized L-tryptophan concentration $(4 \mathrm{mg} / \mathrm{ml})$. Different $\mathrm{pH}$ levels such as 3, 5, 6, 7, 8 and 9 were maintained at 3, 5, 7 and 10 days incubation period. The bacterial strain produced minimum amount of IAA at $\mathrm{pH}$ 3. Maximum IAA production was achieved $39.12 \mu \mathrm{g} / \mathrm{ml}$ at $\mathrm{pH} 7$ of the culture medium (Fig. 4).

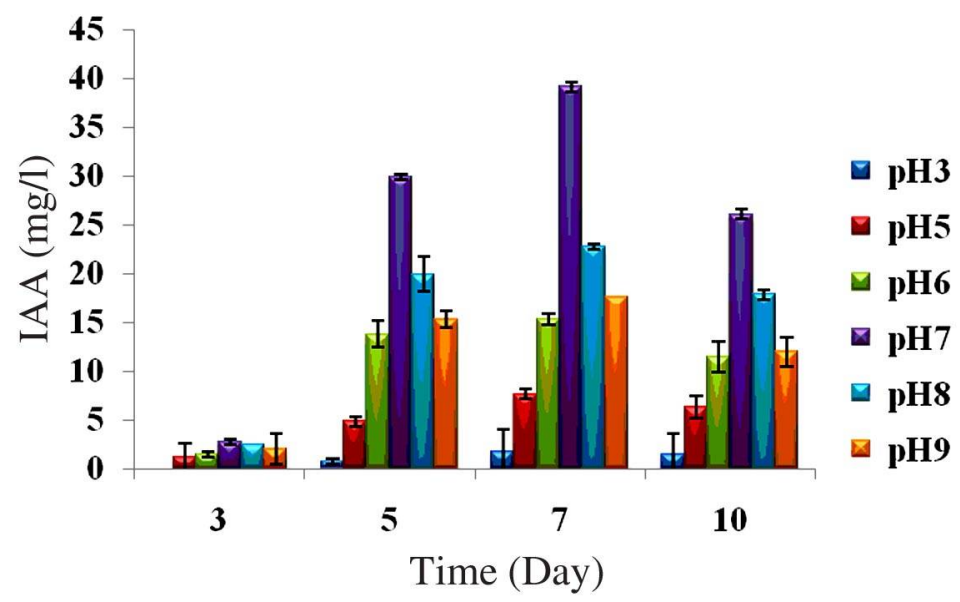

Fig. 4. Production of IAA by B. cepacia UPMB3 at different $\mathrm{pH}$. Each value is the mean of 3 replications. Vertical bars represent standard error.

IAA production decreased at $\mathrm{pH}$ 9.0. Acidic or high alkaline $\mathrm{pH}$ level is not suitable for IAA production of $B$. cepacia UPMB3 due to its poor growth. Shirokikh et al. (2007) reported the distribution of Streptomyces sp. from acidic soils is lower than neutral soils. A significant correlation was also observed between bacterial growth and IAA production. According to Madhuri (2011), different Rhizobium strains produced maximum IAA at $\mathrm{pH}$ level 7.0.

The bacterial strain B. cepacia UPMB3 was influenced by the culture conditions and incubation periods as well. Both the static and shaken conditions were tested for the production of IAA. The maximum production of IAA for $B$. cepacia UPMB3 $(50 \mu \mathrm{g} / \mathrm{ml})$ was achieved in shaken condition on seven days of incubation period, which was statistically significant compared to the static condition (Fig. 5). The reason hypothesized that during shaken condition, the bacteria might be able to get maximum L-tryptophan supplied in the culture medium, which could result in more IAA production. 
Ahmad et al. (2005) reported that the production of IAA in fluorescent Pseudomonas isolates increased with an increase of L- tryptophan concentration from 1 to $5 \mathrm{mg} / \mathrm{ml}$ in the majority of isolates. In presence of $5 \mathrm{mg} / \mathrm{ml} \mathrm{of} \mathrm{L-}$ tryptophan, 5 isolates of Pseudomonas produced high levels (41.0 to $53.2 \mu \mathrm{g} / \mathrm{ml}$ ) of IAA at seven days incubation period. Production of IAA, in Bacillus licheniformis MML2501 with a maximum of $23 \mu \mathrm{g} / \mathrm{ml}$ under optimised conditions such as $\mathrm{pH}$ 7.0, temperature $35^{\circ} \mathrm{C}$, L-tryptophan at a concentration of $16 \mathrm{mM}$ and at $200 \mathrm{rpm}$ shaken conditions (Prashanth and Mathivanan, 2010).

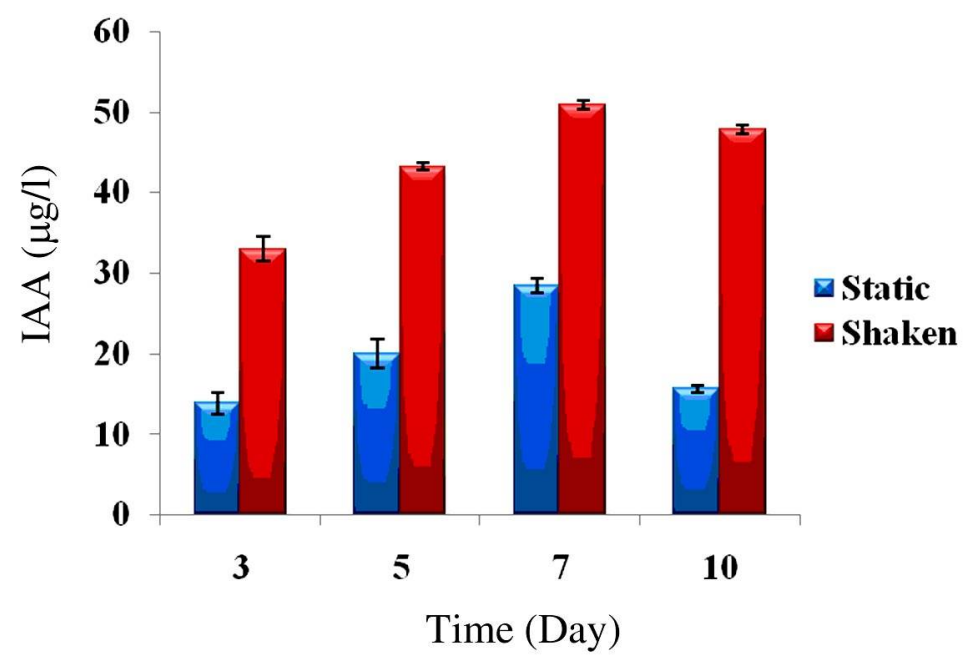

Fig. 5. Effect of culture conditions and incubation period on IAA production by B. cepacia UPMB3. Each value is the mean of 3 replications. Vertical bars represent standard error.

A pot experiment was conducted to study the influence of the bacterial extract (UPMB3) on growth promotion of oil palm germinated seedlings. The results of the pot experiment revealed that among the treatments, T1 (germinated seeds inoculated with B. cepacia UPMB3) and T3 (germinated seeds inoculated with synthetic IAA) showed a positive effect on growth promotion in oil palm seedlings compared with control treatment T2 (non-inoculated germinated seeds). It was observed that the oil palm seedlings treated with B. cepacia UPMB3 produced average 15.66 roots per seedlings respectively whereas the synthetic IAA produced average 9.55 roots per seedling after 4 weeks of planting. The average number of leaves, the shoot, roots and leaf length per seedling also found higher than the control treatment. Results are presented in Table 1 and Fig. 6. 
Table 1. Morphogenic response of oil palm seedlings inoculated with $B$. cepacia UPMB3 supernatant after 4 weeks.

\begin{tabular}{lccc}
\hline \multirow{2}{*}{$\begin{array}{c}\text { Different } \\
\text { parameters }\end{array}$} & \multicolumn{3}{c}{ Treatments } \\
\cline { 2 - 4 } & $\begin{array}{c}\text { T1 } \\
\text { (B. cepacia UPMB3 } \\
+ \text { GOPS) }\end{array}$ & $\begin{array}{c}\text { T2 } \\
\text { (Control) }\end{array}$ & $\begin{array}{c}\text { T3 } \\
\text { (Synthetic IAA + } \\
\text { GOPS) }\end{array}$ \\
\hline Root length* $(\mathrm{cm})^{\text {Ghot length* }(\mathrm{cm})}$ & $17.00 \pm 0.83^{\mathrm{a}}$ & $9.86 \pm 1.75^{\mathrm{b}}$ & $18.11 \pm 0.92^{\mathrm{a}}$ \\
Shy length* $\left.^{*} \mathrm{~cm}\right)$ & $1.86 \pm 0.35^{\mathrm{cd}}$ & $1.73 \pm 0.12^{\mathrm{cd}}$ & $1.90 \pm 0.12^{\mathrm{cd}}$ \\
No. of leaves* $^{*}$ & $4.50 \pm 1.39^{\mathrm{cd}}$ & $1.33 \pm 0.14^{\mathrm{d}}$ & $3.07 \pm 0.32^{\mathrm{cd}}$ \\
No. of roots $^{*}$ & $2.00 \pm 0.00^{\mathrm{cd}}$ & $1.33 \pm 0.28^{\mathrm{d}}$ & $1.66 \pm 0.16^{\mathrm{cd}}$ \\
\hline
\end{tabular}

*Average GOPS = Germinated oil palm seeds. Values followed by the same letter are not significantly different according to LSD test at $\mathrm{p}<0.05$ level.
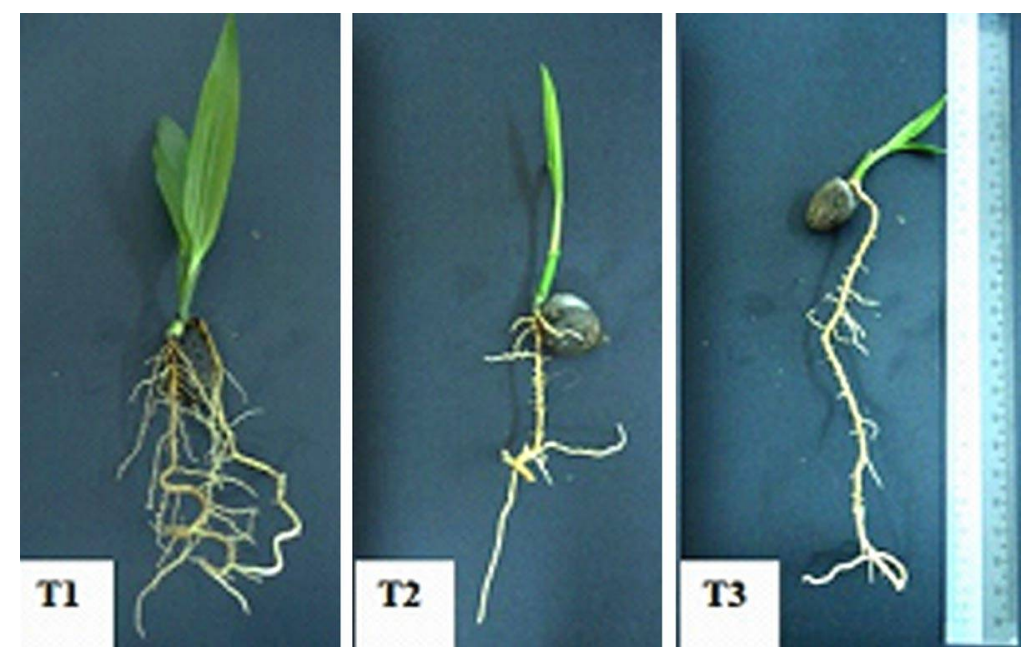

Fig. 6. Influence of phytohormones in different treatments on morphogenic response of oil palm seedlings in pot experiment. T1: B. cepacia UPMB3 + oil palm seedling, T2: Untreated oil palm seedling, T3: Synthetic IAA + oil palm seedling.

This result confirmed that IAA produced by the bacterial strain B. cepacia UPMB3 in the culture filtrate plays a role in plant growth promotion of oil palm seedlings. Seed treatment of Bacillus licheniformis MML2501 in groundnut showed a significant increase in seed germination, plant growth and yield under potted plant experiments (Prashanth and Mathivanan 2010). El-Tarabily (2008) reported that Streptomyces spp. from a tomato rhizosphere had the ability to produce IAA and improved tomato growth by increasing root dry weight. The genus Burkholderia has shown to be the most widespread rice growth promoting bacteria able to produce plant hormones. The application of these PGPR in 
greenhouse and/or field experiments showed, in most cases, a statistically significant increase in seed germination, weight and length of the plant, which means a better grain production efficiency (Rashedul et al. 2009).

Results showed that the rhizobacterial strain UPMB3 of Burkholderia cepacia has the ability to produce IAA which may enrich plant growth promotion.

\section{Acknowledgement}

The authors thank the authorities of Fundamentals Research Grant Scheme of Universiti Putra Malaysia, for providing the financial support to carry out this work.

\section{References}

Ahmad FL and Khan MS (2005) Indole acetic acid production by the indigenous isolates of Azotobacter and fluorescent Pseudomonas in the presence and absence of tryptophan. Turk. J. Biol. 29: 29-34.

Bhavdish N, Johri A, Sharma J and Virdi S (2003) Rhizobacterial diversity in India and its influence on soil and plant health. Adv. Biochem. Eng. Biotech. 84: 49-89.

Datta C and Basu PS (2000) Indole acetic acid production by a Rhizobium species from root nodules of a leguminous shrub, Cajanus cajan. Microbiol. Res. 155: 123-127.

El-Tarabily KA (2008) Promotion of tomato (Lycopersicon esculentum Mill.) plant growth by rhizosphere competent 1-aminocyclopropane-1-carboxylic acid deaminaseproducing streptomycete actinomycetes. Plant and Soil 308: 161-174.

Idris EE, Iglesias EJ, Talon $\mathbf{M}$ and Borriss R (2007) Tryptophan-dependent production of indole-3-acetic acid (IAA) affects level of plant growth promotion by Bacillus amyloliquefaciens FZB42. MPMI. 20: 619-626.

Karnwal A (2009) Production of indole acetic acid by fluorescent Pseudomonas in the presence of L-tryptophan and rice root exudates. J. Plant Pathol. 91: 61-63.

Madhuri M (2011) Screening of rhizobia for indole acetic acid production. Ann Biol Res. 2(4): 460-468.

Paulina EDL, Santos R, Bustillos C, and Jesu' SCM (2001) Burkholderia, a genus rich in plant-associated nitrogen fixers with wide environmental and geographic distribution. Appl. Environ. Microbiol. 67(6): 2790-2798.

Prashanth S and Mathivanan N (2010) Growth promotion of groundnut by IAA producing rhizobacteria Bacillus licheniformis MML2501. Arch Phytopathol Plant Protec. 43: 191-208.

Rashedul IM, Madhaiyan M, Deka Boruah HP, Yim W, Lee G and Saravanan VS (2009) Characterization of plant growth-promoting traits of free-living diazotrophic bacteria and their inoculation effects on growth and nitrogen uptake of crop plants. Microbiol. Biotechnol. 19: 1213-22.

Ritika KR, Ajay K, Amit K, Sandip P, Amit P and Mohinder K (2012) Indole acetic acid production by fluorescent Pseudomonas isolated from the rhizospheric soils of Malus and Pyrus. Recent Res. Sci. Technol. 4: 06-09. 
Shirokikh IG, Zenova GM, Merzaeva OV, Lapygina EV, Batalova GA and Lysak LV (2007) Actinomycetes in the prokaryotic complex of the rhizosphere of oats in a soddy-podzolic soil. Eur Soil Sci. 40: 158-162.

Tien TM, Gaskins MH and Hubbell DH (1979) Plant growth substances produced by Azospirillum brasilense and their effect on the growth of pearl millet (Pennisetum americanum L.). AEM 37: 1016-1024.

Zaiton S, Sariah M and Zainal MA (2006) Isolation and characterization of microbial endophytes from oil palm roots: Implication as biocontrol agents against Ganoderma. The Planter 82: 587-597. 